\title{
ESTÁGIO DOCENTE COMO PRÁTICA PEDAGÓGICA
}

\author{
TEACHER'S STAGE AS TEACHING PRACTICE
}

\author{
PRÁCTICA DOCENTE COMO PRÁCTICA PEDAGÓGICA
}

\author{
Aline Sberse Sengik'; Jordana Wruck Timm²; Claus Dieter Stobäus ${ }^{3}$
}

\section{RESUMO}

Este artigo busca refletir sobre a relevância do estágio docente na formação de professores, durante a realização de um Curso de Formação Pedagógica ou de Mestrado/Doutorado. Nesse sentido, acredita-se que a prática realizada em sala de aula, pelo profissional estagiário pode e deve ser melhor instrumentalizado pedagogicamente. Faz-se uma análise baseada nas Diretrizes Curriculares Nacionais para a Formação de Professores da Educação Básica (BRASIL, 2002), sendo adotado para o referencial teórico, entre outros, Freire (2009), Nóvoa (1995), Palombini (2004), Pimenta; Lima (2005/2006), Ramirez; Stobäus (2010), Tardif; Lessard (2005), Veiga (2010). Trata-se de uma reflexão teórico-prática sobre a experiência de estágio docente realizado para a disciplina de "Estágio Supervisionado II", ao término do Programa Especial de Formação Pedagógica da Universidade de Caxias do Sul. O estudo teve como foco as análises das interações vivenciadas entre a professora e os alunos e analisou-se as possíveis resistências e entraves que essas relações ocasionam em sala de aula. Assim, possibilita comentar que o estágio é fundamental para a preparação do futuro professor, enquanto prática pedagógica, à medida que permite lidar com (im)previsibilidades, que envolvem o trabalho docente e que integra as teorias com as práticas; repensando, reavaliando e ressignificando suas ações em sala de aula, permitindo (re)conhecer realidades escolares, intervir, (re)avaliar (resultados pessoais e profissionais), possibilitando a esse futuro profissional uma maior flexibilidade perante as diversas demandas que resultam do trabalho docente.

PALAVRAS-CHAVE: Estágio. Docência. Prática pedagógica. Educação.

\footnotetext{
${ }^{1}$ Mestre em Educação (UCS), Psicóloga da Prefeitura Municipal de Tapes/RS. E-mail:alinesengik@hotmail.com

2 Doutora em Educação (PUCRS). Professora Colaboradora no Programa de Pós-Graduação em Educação (URI/FW). E-mail: jordana@uri.edu.br

${ }^{3}$ Pós-Doutor em Psicologia - Universidad Autonoma de Madrid (UAM/ES) - Madrid, Espanha. Doutor em Educação - Universidade Federal do Rio Grande do Sul (UFRGS) - Porto Alegre, RS - Brasil. Professor titular Pontifícia Universidade Católica do Rio Grande do Sul (PUCRS) - Porto Alegre, RS - Brasil. E-mail: stobaus@pucrs.br
}

Submetido em: 02/05/2018 - Aceito em: 10/07/2018 


\section{ABSTRACT}

This article aims to reflect on the relevance of teaching internship in teacher's education, during performing a Course of Pedagogical Training or Master/Doctorate. In this sense, it is believed that the practice carried out in the classroom by the in stage professional can and should best instrumentalize he/her pedagogically. It was made an analysis based on the National Curriculum Guidelines for the Basic Education Teacher Training (BRAZIL, 2002), and adopted for the theoretical referential, among others, Freire (2009), Nóvoa (1995), Palombini (2004), Pimenta; Lima (2005/2006), Ramirez; Stobäus (2010), Tardif; Lessard (2005), Veiga (2010). This is a theoretical and practical reflection on teacher's education experienced on the discipline "Supervised Stage II", at the end Special Program of Teacher Education, at the University of Caxias do Sul. The research focused on the analysis of experienced interactions of the teachers with their students, and they analyzed about the possible resistances and obstacles that these relations can cause in the classroom. Allows comments that the stage is critical in the preparation of future teachers while teaching practice, as it allows to handle (im)predictabilities involving the teaching work and integrating theories with practices, rethinking, reevaluating and giving new meaning to their actions in the classroom. Also allows (re)know school realities, intervene, (re)assess (personal and professional results), making it possible for this future professional to be more flexible in face of the various demands that result from teaching.

KEYWORDS: Internship. Teaching. Pedagogical practice. Education.

\section{RESUMEN}

Este artículo busca reflexionar sobre la relevancia de la práctica docente en la formación de profesores, durante la realización de un Curso de Formación Pedagógica o de Maestría/Doctorado. En ese sentido, se cree que la práctica realizada en el aula por el profesional en prácticas puede y debe mejor instrumentalizado pedagógicamente. Se hace un análisis basado en las Directrices Curriculares Nacionales para la Formación de Profesores de la Educación Básica (BRASIL, 2002), para el cual fue adoptado para el referencial teórico, entre otros, Freire (2009), Nóvoa (1995), Palombini (2004), Pimenta; Lima (2005/2006), Ramirez; Stobäus (2010), Tardif; Lessard (2005), Veiga (2010). Se trata de una reflexión teórico-práctica sobre la experiencia de práctica docente realizada para la disciplina de "Práctica Supervisada II", al término del Programa Especial de Formación Pedagógica de la Universidad de Caxias do Sul. El estudio tuvo como foco los análisis de las interacciones vivenciadas entre la profesora y los alumnos, y se analizó las posibles resistencias y trabas que esas relaciones ocasionan en el aula. Así, permite comentar que la práctica supervisada es fundamental para la preparación del futuro profesor, en cuanto práctica pedagógica, a medida que permite lidiar con (im)previsiones que involucran el trabajo docente y que integra las teorías con las prácticas; repensando, reevaluando y resignificando sus acciones en el aula, permitiendo (re)conocer realidades escolares, intervenir, (re)evaluar (resultados personales y profesionales), permitiendo a ese futuro profesional una mayor flexibilidad ante las diversas demandas que resultan del trabajo docente.

PALAVRAS-CLAVE: Práctica. Enseñanza. Práctica pedagógica. Educación. 


\section{INTRODUÇÃO}

O presente texto originou-se da ideia de discutir sobre a prática de estágio realizada ao término do Curso de Formação Pedagógica efetuado na Universidade de Caxias do Sul, por uma das autoras, o qual teve como foco as interações vivenciadas entre a professora e seus alunos e, sobretudo, a possibilidade de reflexões sobre a importância do estágio docente como oportunidade para o aprender a fazer e refazer suas práticas pedagógicas.

Destacam-se as reflexões, nas quais possibilitaram as discussões entre os autores considerando a experiência, que também, teve a co-autora, enquanto aluna nos Cursos de Mestrado e Doutorado, e como professora estagiária no Curso de Pedagogia.

Nesse sentido, buscou-se uma reflexão teórico-prática sobre aspectos considerados relevantes, durante o estágio docente, como o cumprimento de metas e as interações com os alunos. Neste contexto, revisou-se ideias sobre a formação de professores, tendo em vista sua realização em sala de aula, pelo estagiário, que permite a prática e a reflexão sobre sua instrumentalização pedagógica.

Assim, o texto está subdividido em dois tópicos principais: "estágio docente: educação, conhecimento e ensino" e "experiência em estágio docente". No primeiro são apresentados os conceitos de Educação, Conhecimento e Ensino; no segundo são abordadas questões vivenciadas durante o estágio docente e seus desdobramentos; em seguida, algumas considerações finais.

\section{ESTÁGIO DOCENTE: EDUCAÇÃO, CONHECIMENTO, APRENDIZAGEM E ENSINO}

Pensar sobre o estágio docente implica refletir sobre diversos conceitos que envolvem sua realização: educação, conhecimento, aprendizagem e ensino. De acordo com Severino (2004, p. 11), a Educação “É a prática mais humana, considerando-se a profundidade e a amplitude de sua influência na existência do homem [...] é a prática fundamental da espécie, distinguindo o modo de ser cultural dos homens do modo natural de existir dos demais seres vivos".

Nessa perspectiva, a Educação promove o acesso aos bens considerados culturais, possibilita ao ser humano a possibilidade de poder transformar-se e modificar a sociedade em que vive e atua. Assim, ao olhar para o docente percebemos que pode desempenhar uma função sociocultural especial, em um amplo sentido, auxiliando seu aluno na conscientização, na compreensão do mundo, na construção autônoma e significativa de conhecimentos.

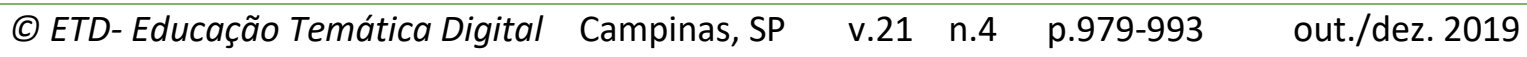


Destaca Freire (2009, p. 38) que "a prática docente crítica, implicante do pensar certo, envolve o movimento dinâmico, dialético entre o fazer e o pensar sobre o fazer". A partir disso, o sujeito pode auxiliar a sociedade em que vive tornar-se mais justa, flexível, dinâmica e inclusiva, na qual é capaz de exercitar o papel transformador que a Educação pode lhe oferecer.

Para Luckesi et. al. (1987, p. 47), "na medida em que agimos, buscamos compreender o mundo no qual e com o qual agimos e, na medida que o compreendemos, cuidamos de reordenar e reorientar nossa ação". Nesse sentido, o papel do professor é fundamental, assim como seu entendimento sobre a concepção acerca de como o sujeito aprende, tendo em vista que, de acordo com Azevedo (2010), somente compreendendo como se dá a aprendizagem é possível planejar um ensino mais adequado.

Para Morin (2001), o ensino tem como missão transmitir uma cultura que permita entender a condição humana e que ajude o indivíduo a viver com mais qualidade, instigando a curiosidade, oportunizando questionamentos e reflexões, além de tentar conseguir promover um modo de pensar mais 'livre e aberto'.

O conhecimento, que é construído por meio das relações com os outros e/ou com os objetos de estudo, pode ser entendido como "o produto de um enfrentamento do mundo realizado pelo ser humano, que só faz sentido, na medida em que o produzimos e o retemos como um modo de entender a realidade, que nos facilite e nos melhore o modo de viver [...]", diz Luckesi et. al. (1987, p. 48). Portanto, para que haja promoção desse processo de aprendizagem mais livre, criativa, consciente, autônoma e, acima de tudo, reflexiva e crítica, de parte do aluno, parece ser necessário oportunizar que seja o agente do seu próprio processo educativo, tendo de ser isso levado em conta no processo de ensino, de forma que sejam, assim, processos interligados.

Dessa forma, reconhece-se a escola como local, na qual se pode propiciar o acesso a informações acumuladas historicamente e que considere os conhecimentos prévios, a cultura e as motivações trazidas pelo estudante, pois é pela interação com o professor, seus colegas e no diálogo com a realidade que será possível que esse estudante crie e construa o seu saber, não o que outrem quer que ele construa, sejam pais, docentes ou outra pessoa. Em meio a toda essa complexidade, que envolve os processos de ensinar e os de aprender, acredita-se que um docente, com bom preparo teórico-metodológico e técnico, possa oferecer ao estudante um ensino que propicie elementos para aprendizagens consideradas significativas e relevantes.

Assim, justifica-se uma formação mais aprofundada, na qual se destaca a importância do estágio docente, como essa possibilidade de vivenciar atividades desenvolvidas em sala de 
aula que abrangem, antes de sua atuação docente, ainda em sua formação, uma espécie de 'laboratório', não apenas as discussões sobre conteúdos e formas a serem trabalhadas com seus alunos, mas também a oportunidade de acompanhar o aprendizado do seu aluno e as implicações dessas interações. Diante desse entendimento de elementos essenciais durante esses processos, o próximo subtítulo destina-se, justamente, a tratar da experiência vivida pelo estagiário.

\section{RESULTADOS: EXPERIÊNCIAS EM ESTÁGIO DOCENTE}

Docência, no sentido etimológico, tem origem no latim docere, que significa indicar, mostrar, ensinar, instruir, dar a entender. Já no âmbito "mais" formal, a docência se refere ao trabalho dos professores, função que esses desempenham e que frequentemente ultrapassa a atividade de somente 'dar aula', aponta Veiga (2010). Para Tardif e Lessard (2005, p. 8), a docência é uma atividade complexa "[...], compreendida como uma forma particular de trabalho sobre o humano, ou seja, uma atividade em que o trabalhador se dedica ao seu 'objeto' de trabalho, que é justamente outro ser humano, no modo fundamental de interação humana".

Nesse sentido, conforme os mesmos autores, o principal objeto de trabalho do docente é ensinar, para que ocorra a aprendizagem dos seus alunos, preferencialmente, através de interatividade. Quando o professor entra em uma sala de aula, ele abre espaço para que sua atividade profissional se desenvolva estabelecendo interação com um ou vários alunos, para que a aprendizagem se concretize nesse contexto.

É por essa razão que a docência adquire um caráter mais desafiador. O trabalho do professor ocorre em uma instituição social e cultural chamada escola, seja ela atualmente a sala de aula formal, seja em Educação a Distância - EAD, seja em uma sistematização nãoformal, ou ainda informalmente, na qual ele interage o tempo todo com as pessoas. Além disso, é necessário observar que o professor trabalha com uma turma, ou seja, com um grupo, consideravelmente, numeroso. Entende-se então, que além de encontrar uma maneira e utilizar determinada metodologia ao ensinar para um coletivo, ele precisa considerar que a aprendizagem (subjetiva) de cada aluno é individual.

Esse processo não é simples e exige do docente um olhar sobre diversos fenômenos grupais que podem surgir em termos de comunicação, cooperação, coesão, competição, antipatia, simpatia, entre tantos outros pontos que se pode considerar, como destaca Chaves (2014). Ao observar esses movimentos, o professor desenvolve com seu grupo habilidades para fazer negociações e criar/utilizar alternativas, na tentativa de evitar resistências e/ou lidar com os entraves que podem prejudicar a participação e a produção grupal. 
Ao considerar todos esses aspectos, na sequência, descrevem-se algumas situações experienciadas nos estágios docentes, inicialmente o realizado como requisito curricular para a certificação, pelo Programa Especial de Formação Pedagógica, da Universidade de Caxias do Sul, pela autora do presente texto. Esse curso, realizado na modalidade EAD, possibilita ao profissional portador de diploma de Curso Superior (nas modalidades Bacharelado ou Tecnologia), a habilitação para exercer a docência em escolas públicas ou privadas de Ensino Médio ou Ensino Técnico.

Nesse Curso, durante dois módulos, o profissional é preparado com o estudo em diversas disciplinas (Filosofia, Sociologia, Antropologia, Psicologia, Políticas Públicas e outras) e também, realiza um estágio de co-participação docente para, posteriormente, ingressar na sala de aula, como professor titular (o estágio é realizado de forma presencial). A ideia é que esses conhecimentos teóricos possam subsidiar a formação apropriada do futuro docente, envolvendo uma prática reflexiva, investigativa e a intervenção na comunidade escolar. Para Pimenta e Lima (2005/2006, p. 12), o papel das teorias:

É o de iluminar e oferecer instrumentos e esquemas para análise e investigação, que permitam questionar as práticas institucionalizadas e as ações dos sujeitos e, ao mesmo tempo, se colocar elas próprias em questionamento, uma vez que as teorias são explicações sempre provisórias da realidade.

O que acontece é que mesmo um profissional bem preparado teoricamente não pode antever as diversas interações que podem ser estabelecidas em seu grupo de alunos. Nesse sentido, Tardif e Lessard (2005) destacam que a escola não pode ser concebida, como um espaço físico unicamente, que seja neutro, mas ela é um espaço sociocultural, visto que nela, não raras vezes, reproduzem-se situações e relações cotidianas, evidenciando-se praticamente as mesmas dificuldades e situações imprevisíveis com as quais o professor vai lidar mais adiante, porém aqui elas são mais "controláveis" pela situação de "supervisão no treinamento em serviço". Assim, dentro da sala de aula, é o elemento humano em interação que prevalece, o trabalho docente materializa-se na relação com seus alunos.

De acordo com Nóvoa (1995), as situações que o professor enfrenta e, na maioria das vezes consegue mesmo resolver, apresentam características singulares, exigindo respostas rápidas e, às vezes, únicas. Se o professor estiver bem preparado, ou seja, se possuir uma boa formação teórica e prática, embora nem sempre consiga, ele terá melhores condições para solucionar esses impasses inerentes ao processo educativo. Esse aperfeiçoamento, antes de ele estar sozinho, parece tão necessário que, cada vez mais são atribuídas novas funções à escola e, consequentemente, ao trabalho docente, exigem um preparo ainda mais abrangente.

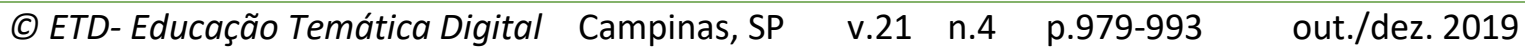


Dessa forma, o estágio docente é de grande relevância, uma vez que propicia ao futuro docente experienciar o trabalho realizado pelo professor que o acompanha, e que envolve, além da interação com seus alunos e com outros colegas, o planejamento dessas aulas, limites como tempo, ritmo e rotinas escolares e ainda, conhecimentos e habilidades para lidar com circunstâncias coletivas e fenômenos grupais, já mencionados, que surgem durante as aulas. Para Pimenta e Lima (2005/2006, p. 6), o estágio:

[...] se constitui como um campo de conhecimento, o que significa atribuir-Ihe um estatuto epistemológico que supera sua tradicional redução à atividade prática instrumental. Enquanto campo de conhecimento, o estágio se produz na interação dos cursos de formação com o campo social no qual se desenvolvem as práticas educativas.

Neste trabalho, a prática do estágio é entendida como uma oportunidade de 'ser' professor com algumas das implicações envolvidas na futura atividade como docente. Mostra-se como uma possibilidade de ir a campo, interagir com pessoas, utilizar teorias e ver repercussões nas práticas. À escola tem o papel de receber esse aluno estagiário, abrindo espaço para sua inserção e ofertando, junto a professores mais experientes, a promoção da reflexão sobre a teoria e a prática, a discussão sobre as informações e conhecimentos, as metodologias empregadas, além de poder gerar sentimentos afetivos e sociais com mais significado e valor humano, que mobilizam saberes e afetos, para a formação de identidade.

Conforme Nóvoa (1995), não basta unir conhecimentos, técnicas ou realizar vários cursos se não forem disponibilizados momentos para que o professor repense suas práticas. Nesse sentido, o estágio é a oportunidade dessa socialização, propiciando espaço e tempo para o compartilhamento de experiências e o pensamento crítico, acerca de sua própria (re)ação, facilitando a construção da identidade pessoal/profissional que dá sentido ao 'ser' docente.

A construção da identidade docente é fundamental para a profissionalização docente, pois envolve o delineamento da cultura do grupo, ao qual o profissional busca pertencer somado ás suas experiências pessoais. É no contexto da interação docente e nas oportunidades, em que relatam suas práticas e experiências, que eles se constituem efetivamente professores. O mesmo já foi destacado no trabalho de Ramirez e Stobäus (2010).

Para Tardif e Lessard (2005), a experiência é qualificante, visto que ensinar se aprende ensinando. Dessa maneira, essa é a aprendizagem realizada no dia a dia, in loco, com o progressivo domínio durante situações de trabalho e no alcance de objetivos que dizem respeito à experiência. Assim, especialmente após a aprovação das Diretrizes Curriculares Nacionais para a Formação de Professores, em 2001, a prática não deve ficar reduzida ao 
estágio curricular, de maneira desarticulada, mas deve ser entendida como uma dimensão prática de formação do professor, para articular a relação teoria-prática no interior das disciplinas, nas práticas de ensino e nos estágios supervisionados (BRASIL, 2001).

Cabe destacar que, para Benjamin (2012), a experiência tem relação com a transmissão/comunicação dos mais velhos com os mais jovens. No entanto, mais do que isto, o conceito de experiência aqui adotado é compreendido, pelos autores do presente texto e em consonância com o contexto do relato ora apresentado, como o desenvolvimento de habilidades a partir das vivências e interações que o professor possui junto aos seus alunos.

Tendo explicitado o contexto desse estudo e referenciado teoricamente os principais conceitos adotados, serão abordadas, a partir desse momento, algumas situações vivenciadas, durante a realização do estágio docente, em uma Escola Profissional Técnica de nível médio, integrada ao Ensino Médio, localizada na Região Nordeste do Rio Grande do Sul, trazidas pela estagiária, também autora desse texto.

Nesse sentido, ao longo do texto, merecem destaque as situações vivenciadas pela autora e também, as situações que foram acrescidas com base nas experiências nos estágios da coautora, as quais estão anunciadas previamente, a fim de contribuir para as discussões. É pertinente destacar que, neste texto, tivemos a intenção de abordar sobre as interações estabelecidas, entre as estagiárias e seus alunos, assim como, os avanços e as limitações delas decorrentes.

Sobre a experiência da autora deste texto, o grupo em que lecionou frequentava um terceiro ano e se caracterizava por contar com predominantemente vinte alunos, com idades entre 17 e 19 anos, destes apenas um do gênero feminino. A escolha do tema "O método nas ciências humanas" deu-se em comum acordo, num único encontro, entre a estagiária e as demandas trazidas pela escola, sendo o conteúdo baseado em um capítulo do livro didático adotado de Aranha e Martins (2009), referente à área de conhecimento "Filosofia".

Tendo em vista, que no terceiro ano os estudantes realizam seus estágios, parecia interessante estudar diferentes metodologias, bem como questões que envolvam a seleção, o manuseio e a ética na pesquisa. Desse modo, propôs-se problematizar os métodos utilizados, para o estudo de determinados fenômenos nas ciências naturais e nas ciências humanas, tencionando um planejamento e intervenções didático-pedagógicas em uma perspectiva crítica, concomitante com a proposta da escola.

O planejamento exigido para as cinco aulas obrigatórias de estágio curricular foi organizado previamente e com a aprovação da orientadora. Na experiência aqui descrita, cada um dos cinco períodos, de 45 minutos cada, foi pensado em termos de objetivos gerais 
e específicos, procedimentos, recursos, critérios, instrumentos e avaliação. A estagiária/coautora em suas experiências de estágio também teve a oportunidade de fazer o planejamento de aulas, sempre com supervisão e aprovação prévia dos professores titulares, o que permitiu a ela perceber a importância desse processo, enquanto aprendizagem, para tornar-se professor, já que esse é um dos requisitos necessários na atividade docente.

Essa etapa, que antecede o trabalho do professor em sala de aula é ratificada, por Tardif e Lessard (2005, p. 283) quando discorrem sobre a atividade docente: pois o "trabalho é planejado, programado, controlado: tal dia a tal hora, ele deve trabalhar com tal grupo de alunos, para ensinar tal matéria durante um tempo previsto", e ainda acrescentam que a posição escolar que o professor ocupa na instituição é regida pelas regras dessa organização.

Passado esse primeiro momento, a estagiária/autora teve que lidar com algumas exigências, como apontado pelos mesmos autores (2005, p. 283), que com frequência se opõem: “[...] o professor precisa exercer autoridade e controlar os alunos, mas também motivá-los intrinsecamente [...]", em que o docente deseja seguir seu planejamento, sendo flexível, transformando-o e adaptando-o, conforme as circunstâncias; deseja alcançar seus objetivos de maneira autônoma, guiando-se pelas metas da instituição escolar; deve atender a cada um dos estudantes individualmente, atuando em uma coletividade; entre outras.

Nesse sentido, ansiedades e tensões podem se entrelaçar e, como menciona Palombini (2004, p. 73), "[...] o saber acadêmico mistura-se aos saberes da vida." Essas situações podem ser bastante complexas para o professor, principalmente no que se refere ao ato de exercer sua autoridade em sala de aula. Essa atitude pode ser confundida, algumas vezes, por uma conduta autoritária, especialmente quando o grupo de alunos está acostumado a silenciar e escutar o docente quando esse 'grita' para/com eles.

No que se refere aos planos de aula, de fato sofrem alterações, principalmente quando o professor inclina-se a conhecer melhor seus estudantes, a familiarizar-se com suas preferências, com seus saberes e com suas distintas culturas. Assim, foi destacado pelas estagiárias, que agissem com flexibilidade.

Nas interações estabelecidas nessa experiência, os alunos eram constantemente chamados a participar das discussões e, não raramente, havia necessidade de falar com um tom de voz mais alto. As conversas paralelas, os risos e as piadas, por parte dos estudantes, algumas vezes distraiam e desconcentravam a estagiária/autora, que não conseguia ter a atenção dos mesmos. Isso fez com que ela refletisse acerca de um docente mais experiente, acreditando que esse possa apresentar habilidades mais desenvolvidas, para interpretar as demandas dos alunos e lidar com esses tipos de comportamento, inclusive chegando a 
negociar com eles, em vez de impor-se. Naquele instante, a estagiária/autora sentiu-se impotente e despreparada para conseguir ter a atenção dos alunos.

Essa reflexão também foi vivenciada, pela outra estagiária/coautora, na realização de seus estágios, tanto na disciplina de "Educação e Saúde", quanto na de "História da Educação". Desinteresse e/ou descompromisso perceptíveis na conduta, por parte de alguns alunos, puderam ser observados, no entanto, ambos os professores titulares tinham um manejo apropriado para tratar essas situações, principalmente pautadas no diálogo, certificando a relevância da experiência para o andamento adequado da aula, bem como, a importância de um olhar atento e ponderado, considerando as especificidades de cada aluno. A esse respeito, Tardif e Lessard (2005, p. 287) comentam que:

Em termos filosóficos a experiência do trabalho é a de um "sujeito hermenêutico", quer dizer, de um ator engajado na interpretação ativa das situações de trabalho, interpretação baseada no que ele, de fato, é, e através da qual ela modifica tais situações e, por conseguinte, sua interpretação.

O grande desafio, segundo a estagiária/autora, foi tentar assegurar mais 'ordem' em sala de aula, para poder atrair a atenção dos seus estudantes, pois estes se mostraram, inicialmente, desinteressados para tratar o assunto que era proposto, assim como apresentaram algumas situações que denotaram resistências como, por exemplo, a falta de interesse e/ou de participação nas atividades e discussões, principalmente nas duas primeiras aulas.

As seguintes falas e comportamentos expostos pela estagiária/autora exemplificam e expressam o que foi percebido, quando seus alunos disseram: "não estou entendendo nada" (sic); "dá pra senhora falar de uma forma mais fácil?" (sic); "pra que que a gente precisa saber disso?" (sic). Também, em se tratando de adolescentes 'conectados', havia o uso de celulares, conversas paralelas com tom de voz mais alto; brincadeiras com carrinho, boneca; contos de piadas, com risos, utilização de subterfúgios e pequenas 'mentiras', como quando alguns alunos disseram que tinham sido "chamados" (sic) para realizarem uma atividade prática e pediram para sair no meio da aula, pois a tarefa existia, porém era para ser executada após o término do período.

Seria desonesto referir, segundo a estagiária/autora, que não se sentiu, até certo ponto, 'frustrada' nessas duas primeiras aulas, com a sensação de eminente 'fracasso' em seus propósitos e em conseguir motivar seus estudantes. Até porque, conforme Tardif e Lessard (2005, p. 279): 
[...] as relações dos professores com os alunos se desdobram em diversas modalidades, indo de relações afetivas a relações de poder, passando por toda a sorte de atitudes humanas: alegria, tristeza, dificuldades, dilemas morais, vontade de controle, engajamento pessoal, conflito e colaboração etc.

Entretanto, entender esses processos grupais e compartilhar essas angústias com a sua orientadora fez com que, a futura professora refletisse sobre sua prática, compreendendo o contexto em que estava inserida, o que permitiu rever e reavaliar seus objetivos e repensar sua maneira de conduzir as aulas e ressignificar suas ações.

De acordo com Palombini (2004, p. 84), a supervisão, aqui entendida também como orientação, pode "[...] constituir-se como espaço de continência e ancoragem para a formulação de um estilo do fazer [...]". Essa troca entre professor orientador e seu/sua estagiário/a busca, segundo a autora (p. 84) "[...] dar conta do vivido no âmbito das práticas, possibilitando sua apreensão tanto subjetiva como teórica, transforma essas vivências em experiência fundante de um estilo profissional próprio".

Nesse sentido, a estagiária/autora, na orientação recebida em conversa com sua orientadora/supervisora de curso, considerou como fatores determinantes para sua vivência, enquanto aluna, na mudança de sua ação pedagógica em sala de aula, a percepção, de que a forma como estava abordando o tema não contribuía para manter o interesse dos alunos. Portanto, considerou fundamental, o papel da orientação, para que houvesse mudança em sua prática. Assim, para a autora, enquanto estagiária, o desafio da experiência possibilitou promover diferentes modos, conforme a realidade de cada situação, na relação que se pretendia estabelecer com os estudantes, bem como, na (re)construção da práxis pedagógica.

Para a autora, as orientações adquiridas no estágio, nortearam um novo comportamento da estagiária. Conceitos acerca de como o aluno aprende, bem como a relevância de conhecer a realidade escolar, contextualizando o ensino e propiciando que o aluno seja, de fato, protagonista no processo de sua aprendizagem foram essenciais para 0 crescimento docente e para mudanças na ação da futura profissional.

Diante disso, a autora, na condição de estagiária, destacou que novos rumos se deram, a partir do momento, em que a orientadora/supervisora promoveu um espaço para partilhar informações, dúvidas, ansiedades e sentimentos, o que a orientou, para um melhoramento de sua prática. Nesse momento, foram considerados os acontecimentos e propiciadas reflexões sobre a dinâmica que se dava em sala de aula, o que possibilitou apoiar e orientar, mais apropriadamente, a atitude da estagiária que aos poucos construía sua identidade como profissional da docência. 
Assim, através dessa orientação recebida, a estagiária relata que foi sentindo-se mais apoiada, pois na terceira aula foi observada pela orientadora. O diálogo, as reflexões sobre a postura em sala de aula foram vividas, como uma oportunidade de constituir-se como professora, visando conseguir construir uma identidade docente naquele grupo e naquele momento.

Sobre isso, a outra estagiária/coautora pode avaliar sua experiência com os estágios realizados, no que se refere às orientações dos professores titulares - tanto em suas falas, quanto em suas atitudes - como sempre válidas, especificamente no que diz respeito à contribuição que essa/o prática/estágio propicia ao enfrentamento dos desafios e do futuro exercício da docência. A coautora, ao estagiar na disciplina "Educação e Saúde", destacou, além da habilidade do professor titular, em lidar apropriadamente com distintos eventos que ocorrem em sala de aula, sua disponibilidade, estilo e conhecimento que o tornam referência enquanto docente, tendo em vista o respeito e a flexibilidade, com a qual interage com seus alunos.

Voltando para a experiência da estagiária/autora, diferente do que vivenciado nas primeiras aulas, as duas aulas seguintes ocorreram de maneira mais tranquila, e relata a estagiária/autora que parecia ter acolhido melhor certas características dos seus estudantes, o que efetivamente lhe propiciou o estabelecimento de um vínculo com a turma, já que os alunos demonstraram uma maior aceitação do seu estilo como sua professora, bem como, quanto ao conteúdo trabalhado, permitindo um clima mais favorável, para estabelecer comunicação, cooperação e produção. Os estudantes mostraram-se mais receptivos e participativos promovendo uma maior segurança e espontaneidade, por parte da estagiária/autora.

Nos estágios realizados pela estagiária/coautora, em duas turmas distintas de graduandos em Pedagogia, a mesma não teve a incumbência e nem poderia ministrar aulas sem a presença do professor titular, sendo o seu aprendizado construído, sobretudo, com base nas observações feitas. No entanto, relata ter tido a liberdade e o espaço, desde que, com orientação prévia, pudesse intervir junto aos alunos. No estágio realizado na disciplina, "História da Educação" a estagiária/coautora teve a oportunidade de propor atividades e dinâmicas grupais em todas as aulas. Cada aula tinha quatro créditos, o professor titular ministrava os dois primeiros, enquanto os dois seguintes eram de responsabilidade da estagiária, sobre supervisão do professor, que estava incumbida de fazer trabalhos ou dinâmicas grupais, sobre a temática trabalhada pelo mesmo. Já em sua segunda experiência de estágio docente, na qual ministrou à disciplina "Educação e Saúde", a estagiária/coautora diz ter tido mais autonomia, sem um momento pré-estabelecido para suas interações, porém sempre com a participação do professor titular. 
A avaliação que as estagiárias (autora e coautora) fazem dessas experiências é que o estágio docente permitiu-Ihes refletir sobre, como melhor vivenciar uma formação (in loco, em serviço) que é complexa, pois envolve fazeres, saberes, teoria, prática, administração de modos de ensinar em determinados limites de tempos e espaços, além das interações que podem facilitar ou ocasionar entraves no andamento das aulas.

Evidenciadas essas reflexões das estagiárias, entende-se que, quando a turma 'não produz (adequadamente)', quando não participa (ativamente), não colabora (na maioria dos momentos) e não debate junto ao professor, essas circunstâncias tendem a inviabilizar a promoção de um ambiente mais rico em estímulos e possíveis interações que possam redundar em construção de aprendizagens mais significativas, no processo de ensino proposto.

O desafio hoje, está então em conseguir pensar em uma formação docente que possa contribuir, de fato, para práticas mais satisfatórias, que oportunizem mais possibilidades de (auto)reflexão, apreensão de informações/conhecimentos, ao mesmo tempo que habilidades e atitudes, gerando sentimentos mais positivos e com (re)significações que mobilizem saberes e reafirmando ou ressignificando a identidade desse (futuro) professor. Para tanto, o estágio docente pode ser uma excelente oportunidade para integrar teorias com práticas, permitindo melhor compreender, que as (re)ações do professor são construídas no dia a dia, por meio da interação dele com outros sujeitos (alunos, colegas de profissão, direção, família e demais agentes da comunidade escolar), em determinadas e específicas realidades escolares, articuladas em um projeto de formação continuada.

Desses aspectos fazem parte também, saber lidar com relações humanas, conforme já mencionado por Tardif e Lessard (2005), o trabalho docente envolve a interatividade e, consequentemente, as mais diversas relações podem se estabelecer: comunicação, cooperação, rejeição, dependência, simpatia, antipatia e tantas outras. De fato, não há como sempre conseguir 'controlar' esses fenômenos grupais. Entretanto, observa-se que um professor mais experiente, e com adequado preparo teórico-metodológico e técnico, tende a ter mais habilidades e atitude positiva ao lidar, negociar e agir nessas situações.

\section{CONSIDERAÇÕES FINAIS}

Neste artigo buscou-se refletir sobre a relevância de (re)ler o estágio docente, enquanto prática pedagógica na preparação do futuro docente, durante a formação de professores. O texto teve como foco reflexões sobre situações vivenciadas, como atividades de estágio com seus alunos, comentários de seus respectivos orientadores, circunstâncias atípicas ocorridas em sala de aula etc. pela autora e coautora em seus estágios, que foram amplamente discutidas e confrontadas.

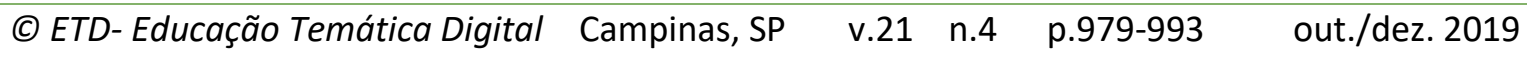


Esse debate permitiu concluir que o estágio é fundamental para a formação docente, surge como uma prática pedagógica que leva a experiência de situações 'futuras no aqui e agora', à medida que integra as teorias com as práticas e, permite (re)conhecer realidades escolares, intervir (enquanto local real e não idealizado), (re)avaliar (resultados pessoais e profissionais, que são merecedores de reparação de outros colegas mais experientes), o que exige desse futuro professor responder a diversas demandas que resultam de um trabalho docente, repensando, reavaliando e ressignificando em seguida, suas próprias ações.

Por fim, e maneira provisória, foi possível perceber, por meio da vivência prática, oportunizada pelo estágio docente e da construção desse texto, a importância de se ter mais flexibilidade, tanto no que se refere aos planos de aula, quanto nas atitudes do professor, algumas 'pitadas' de criatividade e manutenção de bom humor. Nesse sentido, recorre-se, novamente, a pertinência do professor orientador, que promove um espaço, para que o estagiário desenvolva uma postura atenta, interdisciplinar e reflexiva, contribuindo para o enfrentamento dos desafios, que no ambiente escolar aparecem.

Feitas essas considerações, reconhece-se as limitações dessa discussão, no sentido de não ser totalmente generalizável. Apesar do pouco número de aulas que foram descritas, sendo apenas, com dois grupos de (distintos) alunos, em momentos de formação diversos, as reflexões aqui apresentadas, permitiram visualizar sobre interações que são significativas, na formação pessoal e profissional do futuro docente. Sugere-se novos trabalhos que considerem essas experiências aqui descritas que, apesar de singulares, fundamentam para uma formação de melhores e mais saudáveis docentes.

\section{REFERÊNCIAS}

ARANHA, Maria Lúcia de Arruda; MARTINS, Maria Helena Pires. Filosofando: introdução à filosofia. 4. ed. São Paulo: Moderna, 2009.

AZEVEDO, Tânia Maris de. Transposição didática de gêneros discursivos: algumas reflexões. Desenredo - Revista do Programa de Pós-Graduação em Letras da Universidade de Passo Fundo, Passo Fundo, v. 6, n. 2, p. 198- 214, jul./dez., 2010.

BENJAMIN, Walter. Magia e técnica, arte e política: ensaios sobre a literatura e história da cultura. 8. ed. São Paulo: Brasiliense, 2012. (Obras Escolhidas v. I).

BRASIL. MEC. Conselho Nacional de Educação. Parecer $n$ ㅇ 09, de 2001. Institui Diretrizes Curriculares Nacionais para a Formação de Professores da Educação Básica, em nível superior, curso de licenciatura, de graduação plena. Diário Oficial da União, Brasília, 18/01/2002. Seção 1, p. 31. 
CHAVES, Adriana Josefa F. Os processos grupais em sala de aula. Disponível em: http://www.saude.ms.gov.br/controle/ShowFile.php?id=27854. Acesso em: 04 jul. 2014.

FREIRE, Paulo. Pedagogia da autonomia. Rio de Janeiro: Paz e Terra, 2009.

LUCKESI, Cipriano Carlos; BARRETO, Elói; COSMA, José; BAPTISTA, Naidison. Fazer universidade: uma proposta metodológica. São Paulo: Cortez, 1987.

MORIN, Edgar. A cabeça bem-feita. 4. ed. Rio de Janeiro: Bertrand Brasil, 2001.

NÓVOA, António. A Formação da profissão docente. In: NÓVOA, António. (Coord.). Os professores e a sua formação. 2. ed. Lisboa: Dom Quixote, 1995. p. 15- 33.

PALOMBINI, Analice de Lima. Formação profissional e construção de conhecimento em interação com a comunidade: supervisão na Universidade. In: NASCIMENTO, Célia A. Trevisi do; LAZZAROTTO, Gislei D. Romanzini; HOENISCH, Júlio Cézar D.; SILVA, Maria Cristina Carvalho da; MATOS, Rosângela da Luz (Org.). Psicologia e políticas públicas: experiências em saúde pública. Porto Alegre: CRP - 7ạ Região, 2004. p. 73- 94.

PIMENTA, Selma Garrido; LIMA, Maria Socorro Lucena. Estágio e docência: diferentes concepções. Poíesis - Revista do Programa de Pós-Graduação em Educação, Tubarão, v. 3, n. 3/4, p. 5- 24, 2005/2006.

AMIREZ, Vera Lúcia; STOBÄUS, Claus Dieter. Profissionalismo docente e a docência na Educação Superior. In: CELL- CONGRESSO LASALLISTA DE EDUCAÇÃO, 2010, Niterói. Anais..., Niterói- RJ, 2010. p. 10- 16.

SEVERINO, Antônio Joaquim. Prefácio. In: GADOTTI, Moacir. História das ideias pedagógicas. 8. ed. São Paulo: Ática, 2004. p. 11-13.

TARDIF, Maurice; LESSARD, Claude. $\mathbf{O}$ trabalho docente: elementos para uma teoria da docência como profissão de interações humanas. 2. ed. Rio de Janeiro: Vozes, 2005.

VEIGA, Ilma Passos Alencastro. A aventura de formar professores. 2. ed. São Paulo: Papirus, 2010.

Revisão gramatical realizada por:

Caroline Teixeira Fuão da Silva.

E-mail: carolfuao@gmail.com

(C) ETD-Educação Temática Digital Campinas, SP $\quad$ v.21 n.4 $\quad$ p.979-993 $\quad$ out./dez. 2019 